\title{
Unilateral C-1 posterior arch screws and C-2 laminar screws combined with a 1-side C1-2 pedicle screw system as salvage fixation for atlantoaxial instability
}

\author{
Jin Guo-Xin, PhD, and Wang Huan, PhD \\ Department of Orthopaedic Surgery, Shengjing Hospital, China Medical University, Shenyang City, Liaoning Province, China
}

\begin{abstract}
OBJECTIVE Atlantoaxial instability often requires surgery, and the current methods for fixation pose some risk to vascular and neurological tissues. Thus, new effective and safer methods are needed for salvage operations. This study sought to assess unilateral C-1 posterior arch screws (PASs) and C-2 laminar screws (LSs) combined with 1-side C1-2 pedicle screws (PSs) for posterior C1-2 fixation using biomechanical testing with bilateral C1-2 PSs in a cadaveric model.
\end{abstract}

METHODS Six fresh ligamentous human cervical spines were evaluated for their biomechanics. The cadaveric specimens were tested in their intact condition, stabilization after injury, and after injury at $1.5 \mathrm{Nm}$ of pure moment in 6 directions. The 3 groups tested were bilateral C1-2 PSs (Group A); left side C1-2 PSs with an ipsilateral C-1 PAS + C-2 laminar screw (Group B); and left side C1-2 PSs with a contralateral C-1 PAS + C-2 LS (Group C). During the testing, angular motion was measured using a motion capture platform. Data were recorded, and statistical analyses were performed.

RESULTS Biomechanical testing showed that there was no significant difference among the stabilities of these fixation systems in flexion-extension and rotation control. In left lateral bending, the bilateral C1-2 PS group decreased flexibility by $71.9 \%$ compared with the intact condition, the unilateral C1-2 PS and ipsilateral PAS+LS group decreased flexibility by $77.6 \%$, and the unilateral C1-2 PS and contralateral PAS+LS group by $70.0 \%$. Each method significantly decreased C1-2 movements in right lateral bending compared with the intact condition, and the bilateral C1-2 PS system was more stable than the C1-2 PS and contralateral PAS+LS system $(p=0.036)$.

CONCLUSIONS A unilateral C-1 PAS + C-2 LS combined with 1-side C-1 PSs provided the same acute stability as the $\mathrm{PS}$, and no statistically significant difference in acute stability was found between the 2 screw techniques. These methods may constitute an alternative method for posterior atlantoaxial fixation.

http://thejns.org/doi/abs/10.3171/2015.4.SPINE14517

KEY WORDS atlantoaxial fixation; C-1; posterior arch screw; pedicle screw; laminar screw; salvage method; range of motion; cervical

$\mathrm{T}$ HE atlantoaxial complex is an important structure ensuring flexion-extension, bending, and rotation. It is composed of the atlas and axis and their articulating surfaces and is enhanced by the surrounding ligamentous structures. ${ }^{27}$ If these structures are damaged by trauma, inflammatory diseases, tumors, or congenital malformations, the stability of this area will be affected, which can lead to local pain, neurological injury, and even death. Therefore, intervention is often needed for decompression, realignment, and stability.

There is a general consensus that solid intervertebral fusion is best achieved when the fixation minimizes motion. ${ }^{8}$ The methods that have been used in C-1 posterior fixation have included posterior wiring (as described by Gallie $^{10}$ and Brooks ${ }^{2}$ ), which runs the risk of spinal cord injury and instability, ${ }^{13}$ and $\mathrm{C}-1$ clamps with poor flexion, extension, and rotational control. ${ }^{16}$ Transarticular screws ${ }^{22}$ are better for bending and rotational control, but weaker in flexion-extension; ${ }^{32}$ therefore there is a pseudoarthrosis rate. ${ }^{4}$ This technique cannot be used for reduction, and it is technically demanding to avoid vertebral artery (VA) injury.

ABBREVIATIONS LMS = lateral mass screw; LS = laminar screw; PAS = posterior arch screw; $P S=$ pedicle screw; ROM = range of motion; VA = vertebral artery. SUBMITTED May 31, 2014. ACCEPTED April 21, 2015. 
The C-1 lateral mass screw (LMS) was introduced by Goel and Laheri in 1994, ${ }^{12}$ then Harms and Melcher described a modified technique in $2001^{15}$ using polyaxial screws and rods to minimize the risk of VA injury and allow intraoperative reduction. In conjunction with C-2 pedicle screws (PSs), this method provided a similar biomechanical profile compared with the technique of Magerl and Seemann, ${ }^{22}$ and positive clinical results. ${ }^{1}$ Thereafter, some authors ${ }^{21,30,31,34}$ introduced the C-1 PS technique, an alternative fixation method of C-1 LMSs, which placed the screw via the posterior arch into the lateral mass.

Currently, screw fixation has replaced wires or hooks to provide greater rigidity and prevent most postoperative movement. ${ }^{13,16}$ However, these methods have the disadvantage of placing the VA at risk, causing troublesome bleeding and obscure visualization, and when anatomical variation or traumatic/iatrogenic damage occurs, salvage methods (safer to the VA and spinal cord) are necessary. Thus, we designed unilateral C-1 posterior arch screw (PAS) and C-2 laminar screw (LS) fixation combined with a C1-2 PS system as a salvage method (Fig. 1) and compared it to the bilateral C1-2 PS system (as the gold standard) using biomechanical evaluations. To date, no reports have detailed the construct stability of this new technique.

\section{Methods}

\section{In Vitro Biomechanical Evaluation}

Six fresh-frozen upper cervical spines (occiput-C4) with intact ligaments were obtained from donated cadavers. The average age of the cadavers was $68.5 \pm 8.8$ years, with 3 female and 3 male subjects. The specimens were double-bagged and kept frozen at $-20^{\circ} \mathrm{C}$ after they were examined for any anomalies or fractures using radiography. The spines were thawed at $4^{\circ} \mathrm{C}$ for 12 hours, and the tissue surrounding the spine was carefully stripped, except for the ligaments and discs.

For PS placement, the inferior and interior plane of the $\mathrm{C}-1$ pedicle and the interior and superior plane of the C-2 pedicle were detected by probing, and the entry points were selected. A high-speed drill was used to create an opening and then placed along the pedicle. The cavity was identified using the drill, and the screws (diameter 3.5 $\mathrm{mm}$, length $22 \mathrm{~mm}$ ) were placed (Figs. 1 and $2 \mathrm{~A}$ ).

For C-1 PAS placement, the entry point was identified approximately $2 \mathrm{~mm}$ lateral from the middle part of the posterior tubercle on the opposite side of the aimed PAS side (Figs. 1, 2B, and 2C). A high-speed drill was used to create an opening and then placed along the arch. The cavity was identified carefully using the drill, paying careful attention to the VA groove. Multiaxial screws were placed (diameter $3.5 \mathrm{~mm}$, length $22 \mathrm{~mm}$ ).

For the C-2 LSs (diameter $3.5 \mathrm{~mm}$, length $22 \mathrm{~mm}$ ), the entry points were identified at the junction of the C-2 spinous process and lamina (Figs. 1, 2B, and 2C). With the drill along the exposed contralateral lamina, the trajectory was kept slightly lower than the downslope of the lamina to avoid outer cortical or spinal canal breakthrough.

Several wood screws were inserted into the C-4 vertebral body, which was embedded in dental cement to the rostral and caudal structures. During mounting, the speci-
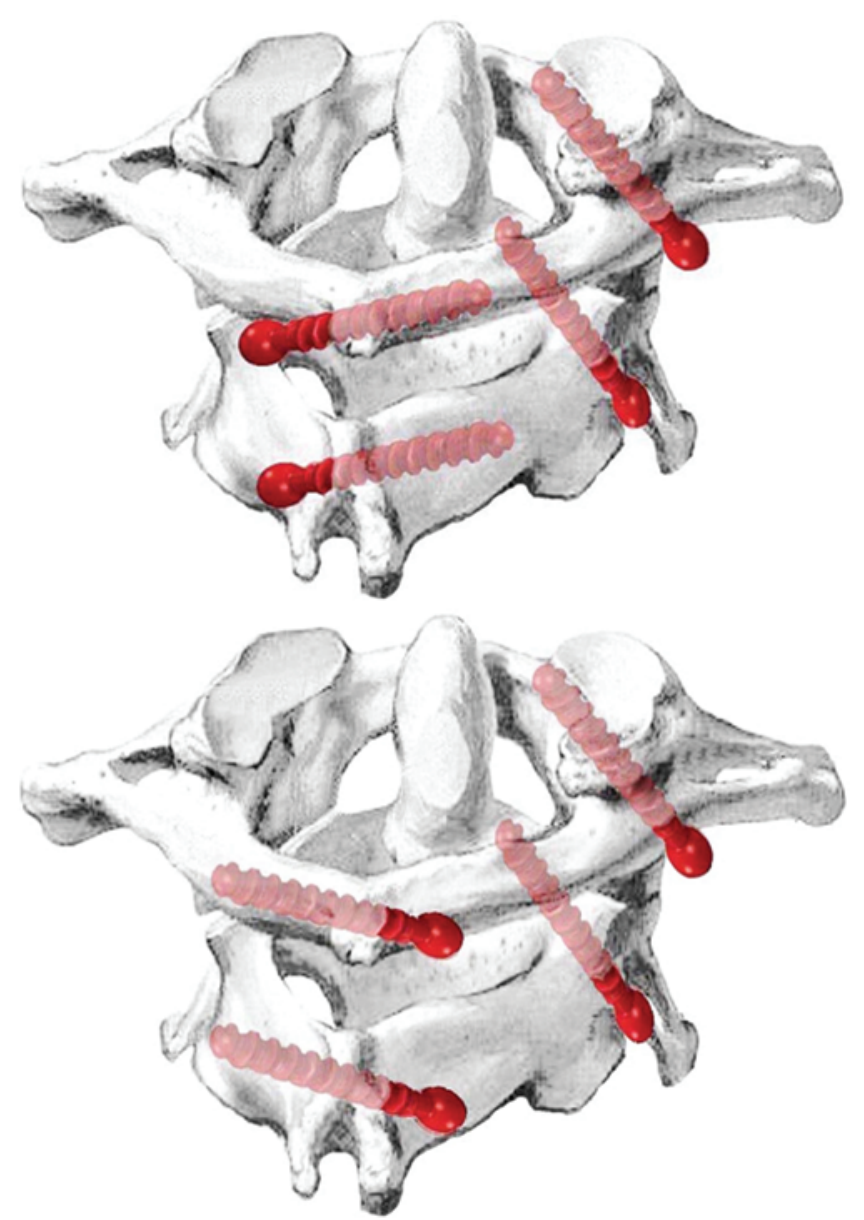

FIG. 1. Illustrations showing unilateral C1-2 PS with ipsilateral C-1 PAS + C-2 LS (upper), and unilateral C1-2 PS with contralateral C-1 PAS + C-2 LS (lower). Copyright Wang Huan. Published with permission. Figure is available in color online only.

men was oriented in the neutral position, with the C3-4 disc space on the horizontal plane. Two threaded rods were fixed to the skull orthogonally to apply pure moment loads. The load-dependent 3D displacements were calculated using a motion capture platform (Vicon Nexus). Three noncollinear markers were attached to the anterior aspects of the occiput and to the vertebral bodies of C-1, $\mathrm{C}-2$, and C-3. Six cameras detected the light reflected by these markers, and the collected data were processed using special software (Vicon Nexus 2).

\section{Motion Measurement}

The prepared specimens were attached to the rigid base in a testing frame. Using a system of loading arms, pulleys, and weights, quasistatic loads were applied to the skull, leading to sequential pure moments of $0,0.5,1.0,1.5,1.0$, 0.5 , and $0 \mathrm{Nm}^{29}$ The moments were applied to generate the following 6 loading modes: extension, flexion, left lateral bending, right lateral bending, left axial rotation, and right axial rotation. To overcome the spine's viscoelastic effects, the specimens were manipulated maximally in all directions for preconditioning at least 3 times prior to the initial tests. Additionally, after each load application, the system was allowed to stabilize for 30 seconds to mini- 

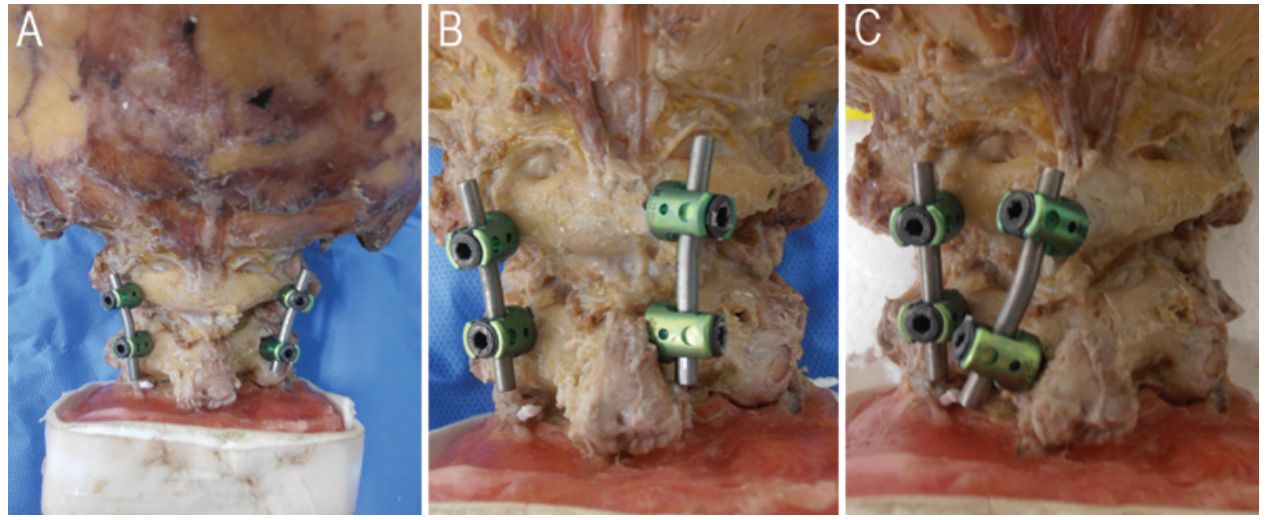

FIG. 2. Photographs of the 3 stabilization systems in place. A: Bilateral C-1 PS + C-2 PS with a screw-rod system (Group A). B: Left side C1-2 PS, with ipsilateral C-1 PAS + C-2 LS with a screw-rod system (Group B). C: Left C1-2 PS, with contralateral C-1 PAS + C-2 LS with screw-rod system (Group C). Figure is available in color online only.

mize creep prior to data collection. The specimens were frequently sprayed with normal saline to prevent drying of the tissue during testing.

\section{Testing Sequence}

The intact spines were tested for load displacement behavior. This step generated baseline values, which were used for subsequent comparisons. The specimens were destabilized by creating Type II odontoid fractures, first by drilling multiple holes at the base of the odontoid, and then by disconnecting the odontoid with a quarter-inch osteotome. Due to the severe instability caused by the fracture, performing motion measurements was difficult, and thus they were collected at the end of the procedure.

\section{Spinal Constructs}

After destabilization, each specimen was stabilized in random order $(\mathrm{n}=6$ for each construct). Once placed, the screws were not removed to avoid any interference with the bone-screw purchase, and they were fixed to the rods correspondingly: 1) bilateral C-1 PS + C-2 PS with a screw-rod system (Group A; Fig. 2A); 2) left-side C-1 + C-2 PS, with ipsilateral C-1 PAS + C-2 LS with a screwrod system (Group B; the C-1 PS was on the same side with the PAS as the sagittal plane crossing the middle of the anterior and posterior arch; Fig. 2B); and 3) left C-1 PS + C-2 PS, with contralateral C-1 PAS + C-2 LS with a screw-rod system (Group C; Fig. 2C).

\section{Data Analysis}

The spatial locations of the markers fixed to the vertebral bodies were recorded using the motion measurement system (as an average of 3 recordings). These spatial locations were transformed into angular rotations referenced to the base plate using rigid body transformation. The rotations of the vertebrae were plotted against the load applied to characterize the load-deformation behavior of the motion segment. The intersegmental rotation across the C1-2 segment was calculated for each of the intact, stabilized, and destabilized specimens. The stabilized specimens were compared with the intact specimens and the destabilization state to evaluate the efficacy of the different techniques for stabilizing the atlantoaxial complex. The term "stability" was used to describe the intersegmental rotation (flexibility) of the motion segment. As the stability increased, the flexibility (rotation angle) diminished and vice versa. The mean ROM values for each group were calculated, and paired comparisons were made between groups using the Wilcoxon paired t-test. Statistical significance was established at $\mathrm{p}<0.01$. The values are presented as the mean \pm $1 \mathrm{SD}$ and as minimum and maximum values.

\section{Results}

The mean flexibility values and standard deviations for the 3 different spine conditions for each mode of loading are summarized in Fig. 3 and Table 1, with the significant differences indicated. The destabilized specimens showed a higher median range of motion (ROM) for all directions than the intact and instrumented specimens. The $\mathrm{p}$ value for the ROM of each group, compared with the destabilized group, was consistently less than 0.05 . The average ROM in the intact specimens was $22.6^{\circ}$ in combined flexion-extension, $15.4^{\circ}$ in total lateral bending, and $55.4^{\circ}$ in axial rotation.

In flexion, the tested implant systems (Group A, bilateral C1-2 PSs; Group B, left-side C1-2 PSs with ipsilateral C-1 PAS + C-2 LS; and Group C, left C1-2 PSs with contralateral C-1 PAS + C-2 LS) significantly decreased C1-2 flexibility by $73.3 \%, 71.9 \%$, and $72.1 \%$, respectively, compared with intact specimens $(\mathrm{p}<0.01)$, and reduced extension by $67.8 \%, 61.9 \%$, and $61.6 \%$, respectively, compared with intact specimens $(\mathrm{p}<0.01)$. In left lateral bending, Group A decreased flexibility by $71.9 \%$ compared with the intact group, Group B by $77.6 \%$, and Group C by $70.0 \%(\mathrm{p}<0.01)$. All these methods reduced the C1-2 movements in right lateral bending compared with the intact group by $68.9 \%, 55.6 \%$, and $51.2 \%$, respectively (all $\mathrm{p}<0.01)$. Group A $\left(2.37^{\circ} \pm 0.70^{\circ}\right)$ was more stable than Group C $\left(3.72^{\circ} \pm 0.73^{\circ} ; \mathrm{p}=0.036\right)$.

In terms of rotational control, Group A was the most stable (left $1.83^{\circ} \pm 0.70^{\circ}$, right $2.13^{\circ} \pm 1.04^{\circ}$ ), followed by Group C (left $2.51^{\circ} \pm 0.73^{\circ}$, right $2.41^{\circ} \pm 0.68^{\circ}$ ) and Group B (left $3.18^{\circ} \pm 0.80^{\circ}$, right $3.31^{\circ} \pm 0.78^{\circ}$ ); however, these differences were not statistically significant (Table 1). 


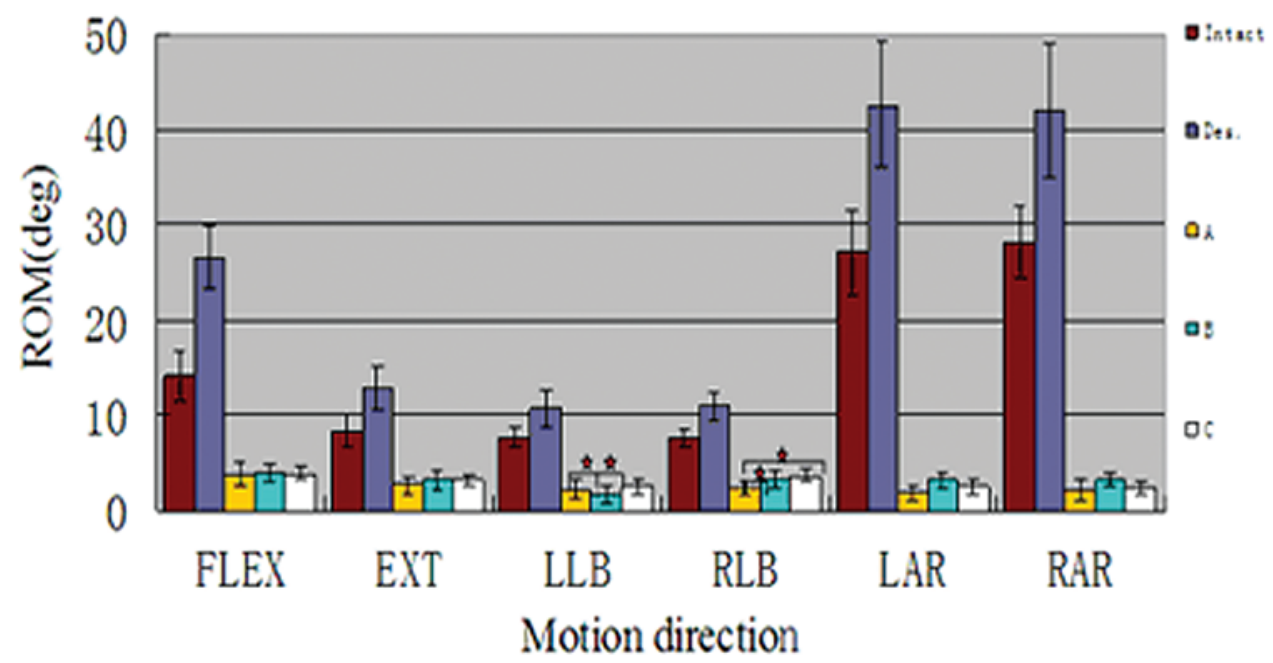

FIG. 3. C1-2 ROM (mean \pm SD) for all tested conditions under $1.5 \mathrm{Nm}$ in 6 directions. Des. = destabilization; EXT = extension; FLEX = flexion; $L A R=$ left axial rotation; $L L B=$ left lateral bending; $R A R=$ right axial rotation; $R L B=$ right lateral bending; Star $=p$ $<0.01$. Figure is available in color online only.

\section{Discussion}

The atlantoaxial joint is the most mobile part of the cervical spine, and solid intervertebral fixation is needed to minimize motion and promote healing. The C-1 LMS is a common method for $\mathrm{C}-1$ fixation but it is technically demanding, especially when the lateral mass is obscured by a thick posterior arch, ${ }^{39}$ ponticulus posticus,${ }^{17}$ anomalous VA, ${ }^{17,28,35,37}$ or a large paravertebral venous plexus. ${ }^{21}$ Goel et al. reported 2 patients who required an alternative method and only 1-side LMS was completed in 9 cases. ${ }^{11}$ Otherwise, the risk of damage to the greater occipital nerve is present, and air embolism has also been reported. ${ }^{2}$ And if the C-1 LMS is inserted bicortically via the Harms technique, it may put the anterior structures (hypoglossal nerve and internal carotid artery) at risk..$^{3,4}$

The C-1 PS, placed via the posterior arch into the lateral mass, is an alternative method to control venous bleeding. It has been shown that a unicortical C-1 PS was stiffer than a unicortical C-1 LMS.7,21,39 However, it has been shown that $7.5 \%$ of $\mathrm{C}-1$ pedicles were less than 3.5 $\mathrm{mm}^{3}$, which means they were not suitable for PS placement. Thirteen percent of C-1s with ponticulus posticus may give the false appearance of a pedicle and pose a con- siderable risk. ${ }^{38}$ As a C-1 PS is placed via the posterior arch, VA injury risk exists, which may cause severe bleeding and difficult hemostasis.

During upper cervical surgery, the use of these methods is influenced by anatomical constraints, such as congenital narrowing of the pedicle or VA aberrations, a large venous plexus, and the surgeon's experience, which may involve the risk of actual injury to one side of the VA or may be suspected by trauma or iatrogenic injury. Because bilateral VA injury may cause severe complications, protecting the contralateral side is necessary, and safer methods are needed.

Kelly et al. ${ }^{18}$ designed a novel C-1 locking plate and found that motion at the $\mathrm{C} 1-2$ level was significantly reduced in all loading modes, except for right lateral bending. However, this method may influence the graft, and drilling on the posterior arch could be dangerous to the spinal cord.

Wright $^{36}$ proposed the use of C-2 LSs, which were shown to provide acute stability in flexion-extension, bending, and rotation equivalent to $\mathrm{C}-2$ pars screws by biomechanical analysis. ${ }^{20}$ Through 1000 cycles of axial rotation, C-2 LS constructs showed no difference from PS constructs in terms of their stability in rotation. ${ }^{33} \mathrm{Ad}-$

TABLE 1. Range of motion at $1.5 \mathrm{Nm}$ for each of 6 motion directions in both groups*

\begin{tabular}{|c|c|c|c|c|c|c|}
\hline \multirow[b]{2}{*}{ Motion Direction } & \multicolumn{6}{|c|}{$\mathrm{ROM}\left({ }^{\circ}\right)$} \\
\hline & Flexion & Extension & LLB & RLB & LAR & RAR \\
\hline Intact & $14.18 \pm 2.66$ & $8.42 \pm 1.74$ & $7.77 \pm 1.07$ & $7.62 \pm 0.90$ & $27.16 \pm 4.47$ & $28.19 \pm 3.77$ \\
\hline Destabilized & $26.66 \pm 3.27$ & $12.87 \pm 2.40$ & $10.77 \pm 1.87$ & $11.02 \pm 1.52$ & $42.59 \pm 6.52$ & $42.00 \pm 6.95$ \\
\hline Group A & $3.79 \pm 1.30 \dagger$ & $2.71 \pm 1.01 \dagger$ & $2.18 \pm 0.96 \dagger$ & $2.37 \pm 0.70 \dagger$ & $1.83 \pm 0.70 \dagger$ & $2.13 \pm 1.04 \dagger$ \\
\hline Group B & $3.98 \pm 0.97 \dagger$ & $3.21 \pm 0.99 \dagger$ & $1.74 \pm 0.86 \dagger$ & $3.38 \pm 0.98 \dagger$ & $3.18 \pm 0.80 \dagger$ & $3.31 \pm 0.78 \dagger$ \\
\hline Group C & $3.96 \pm 0.67 \dagger$ & $3.24 \pm 0.70 \dagger$ & $2.57 \pm 0.90 \dagger$ & $3.72 \pm 0.73 \ddagger$ & $2.51 \pm 0.73 \dagger$ & $2.41 \pm 0.68 \dagger$ \\
\hline $\begin{array}{l}\text { Group } A=C 1-2 \text { PS; } \\
\text { lateral); LAR = left axi } \\
\text { * All values given as } \\
\dagger \text { Significantly differe } \\
\ddagger \text { Significantly differe }\end{array}$ & $\begin{array}{l}\text { p B }=\text { C1-2 PS (u } \\
\text { tation; LLB = left } \\
\pm \text { SD. } \\
\text { m intact. }\end{array}$ & $\begin{array}{l}\text { teral), C-1 PAS } \\
\text { cal bending; RA } \\
\text { (Group A). }\end{array}$ & $\begin{array}{l}\text { LS (ipsilatera } \\
\text { ight axial rota }\end{array}$ & $\begin{array}{l}\text { oup } C=C 1-2 \\
L B=\text { right late }\end{array}$ & $\begin{array}{l}\text { illateral), C-1 P } \\
\text { nding. }\end{array}$ & C-2 LS (contra- \\
\hline
\end{tabular}


ditionally, these constructs posed no risk of injury to the VA and were also shown to be good methods in clinical practice. ${ }^{24}$ In a meta-analysis, Du et al. ${ }^{6}$ found that C-2 LSs could not achieve significant lateral bending stabilization like C-2 PSs or pars screws when combined with C-1 LMSs. Miyakoshi and colleagues ${ }^{25}$ observed that unilateral C-2 PSs + LSs were comparable with bilateral C-2 PS fixation from clinical study.

In 2000, Floyd and Grob $^{9}$ described the use of C-1 translaminar screws to fix grafts during $\mathrm{C} 1-2$ fusion, when the posterior arch was absent. Then, in 2008, Donnellan ${ }^{5}$ used these techniques when the posterior C-1 arch was deficient and obtained excellent postsurgical outcomes. During the operation, the $\mathrm{C}-1$ posterior arch was found to be sufficiently thick to hold screws, and it was tested for the potential to use a C-1 PAS in an anatomical and biomechanical study. It was shown that there was significant control between the C-1 PAS + C-2 PS system and the bilateral C-1 2 PS system for flexion-extension and rotational activity. In lateral bending, the PAS system decreased flexibility by $33.0 \%$ and $24.4 \%$ of the intact specimens, indicating that the PAS system could obtain similar stability to PSs. ${ }^{14}$

The PAS could be a safe surgical alternative, as the entire screw path can be directly visualized or palpated. In addition, this technique appears safe, accessible, and less technically demanding than other C-1 fixation techniques. Because $11 \%$ of atlases were not suited for bilateral PAS because of a flat posterior arch, and $8.49 \%$ of $\mathrm{C}-1$ posterior tubercles were narrow, some patients are not suitable for 2 PASs from opposite sides. ${ }^{14}$ Therefore, we designed a 1-side PS combined with a 1-side PAS and LS to provide a new salvage method.

For the choice of C-1 PS, it was shown that the unicortical C-1 PS had superior resistance to pullout compared with unicortical C-1 lateral mass screws.7,21,39 If C1-2 was displaced after injury, the PS may exhibit stronger resistance. It was also shown that the incidence of a VA anomaly between C-1 and C-2 in Asia was more common than in the US, and it directly affected the safety of C-1 LMS placement, ${ }^{17,28,35,37}$ so fixation must be planned to minimize the VA injury. The choice was also influenced by our clinical experience.

When we tested the biomechanical feasibility of this technique, we found that the hybrid PAS+LS systems could provide the same stability as the PS, and each of these systems was stable and suitable for fixation.

Nagoshi et al. ${ }^{26}$ reported 1 successful case using C-1 PASs (12 $\mathrm{mm})$ as an anchor, and although there were some risks, they believed the PAS was a beneficial choice for C1-2 fixation. Our method decreased the risks of dural tear or spinal cord injury by holding the screw in the posterior arch.

If there was injury to 1 side of the VA or if it was suspected by trauma or iatrogenic injury during screw implantation, placement of the PAS and LS might be easier with less risk to the VA; the PS can be used for reduction and is more stable with a broader clinical applicability. The slight differences in bending control among these methods may correspond to the screw distribution, which was decentralized and far away from the rotation center. And because the 2 methods are combined, the stress of screws in C1-2 may be different. However, this method may run the risk of damage to the dura or spinal cord, and the proper screw trajectory requires extensive exposure and retraction of the neck musculature or the use of a percutaneous approach in larger patients.

It is generally believed that arthrodesis should accompany stabilization in this region and that a combined method can provide at least 1 side with decortication and arthrodesis while the inferior and lateral edges of the posterior arch remain available for grafting. It was found that the fusion rate was significantly lower in the elderly population when using a C-2 LS. ${ }^{24} \mathrm{~A}$ different bone mineral density was shown to be strongly associated with screw pullout strength. ${ }^{33}$ Through the combined method, the 2 sides had different stabilities of pullout strength, and therefore the weakness of using the same method on both sides may be avoided, while further tests, such as C-1 LMS combined with PAS, fatigue tests, and pullout strength assessments of the screws are needed for a more comprehensive biomechanical evaluation of these methods.

\section{Conclusions}

Insertion of C-1 PASs and C-2 LSs are straightforward and impose little risk of injury to the neural and vascular structures as long as the implants remain intraosseous. According to the results of our biomechanical study, combined C-1 PAS and C-2 LS with C1-2 PS fixation may constitute an alternative method for posterior atlantoaxial fixation.

\section{Acknowledgment}

This work was supported by a grant from the National Natural Science Foundation of China (no. 81271995).

\section{References}

1. Aryan HE, Newman CB, Nottmeier EW, Acosta FL Jr, Wang VY, Ames CP: Stabilization of the atlantoaxial complex via $\mathrm{C}-1$ lateral mass and $\mathrm{C}-2$ pedicle screw fixation in a multicenter clinical experience in 102 patients: modification of the Harms and Goel techniques. J Neurosurg Spine 8:222-229, 2008

2. Brooks AL, Jenkins EB: Atlanto-axial arthrodesis by the wedge compression method. J Bone Joint Surg Am 60:279284, 1978

3. Christensen DM, Eastlack RK, Lynch JJ, Yaszemski MJ, Currier BL: $\mathrm{C} 1$ anatomy and dimensions relative to lateral mass screw placement. Spine (Phila Pa 1976) 32:844-848, 2007

4. Currier BL, Todd LT, Maus TP, Fisher DR, Yaszemski MJ: Anatomic relationship of the internal carotid artery to the $\mathrm{Cl}$ vertebra: A case report of cervical reconstruction for chordoma and pilot study to assess the risk of screw fixation of the atlas. Spine (Phila Pa 1976) 28:E461-E467, 2003

5. Donnellan MB, Sergides IG, Sears WR: Atlantoaxial stabilization using multiaxial C-1 posterior arch screws. J Neurosurg Spine 9:522-527, 2008

6. Du JY, Aichmair A, Kueper J, Wright T, Lebl DR: Biomechanical analysis of screw constructs for atlantoaxial fixation in cadavers: a systematic review and meta-analysis. J Neurosurg Spine 22:151-161, 2015

7. Fensky F, Kueny RA, Sellenschloh K, Püschel K, Morlock $\mathrm{MM}$, Rueger JM, et al: Biomechanical advantage of $\mathrm{C} 1$ pedicle screws over C1 lateral mass screws: a cadaveric study. Eur Spine J 23:724-731, 2014 
8. Ferguson RL, Tencer AF, Woodard P, Allen BL Jr: Biomechanical comparisons of spinal fracture models and the stabilizing effects of posterior instrumentations. Spine (Phila Pa 1976) 13:453-460, 1988

9. Floyd T, Grob D: Translaminar screws in the atlas. Spine (Phila Pa 1976) 25:2913-2915, 2000

10. Gallie WE: Fractures and dislocations of the cervical spine. Am J Surg 46:495-499, 1936

11. Goel A, Desai KI, Muzumdar DP: Atlantoaxial fixation using plate and screw method: a report of 160 treated patients. Neurosurgery 51:1351-1357, 2002

12. Goel A, Laheri V: Plate and screw fixation for atlanto-axial subluxation. Acta Neurochir (Wien) 129:47-53, 1994

13. Grob D, Crisco JJ III, Panjabi MM, Wang P, Dvorak J: Biomechanical evaluation of four different posterior atlantoaxial fixation techniques. Spine (Phila Pa 1976) 17:480-490, 1992

14. Jin GX, Wang H, Li L, Cui SQ, Duan JZ: C1 posterior arch crossing screw fixation for atlantoaxial joint instability. Spine (Phila Pa 1976) 38:E1397-E1404, 2013

15. Harms J, Melcher RP: Posterior C1-C2 fusion with polyaxial screw and rod fixation. Spine (Phila Pa 1976) 26:2467-2471, 2001

16. Henriques T, Cunningham BW, Olerud C, Shimamoto N, Lee GA, Larsson S, et al: Biomechanical comparison of five different atlantoaxial posterior fixation techniques. Spine (Phila Pa 1976) 25:2877-2883, 2000

17. Hong JT, Lee SW, Son BC, Sung JH, Yang SH, Kim IS, et al: Analysis of anatomical variations of bone and vascular structures around the posterior atlantal arch using three-dimensional computed tomography angiography. J Neurosurg Spine 8:230-236, 2008

18. Kelly BP, Glaser JA, DiAngelo DJ: Biomechanical comparison of a novel $\mathrm{C} 1$ posterior locking plate with the harms technique in a C1-C2 fixation model. Spine (Phila Pa 1976) 33:E920-E925, 2008

19. Kuroki H, Rengachary SS, Goel VK, Holekamp SA, Pitkänen V, Ebraheim NA: Biomechanical comparison of two stabilization techniques of the atlantoaxial joints: transarticular screw fixation versus screw and rod fixation. Neurosurgery 56 (1 Suppl):151-159, 2005

20. Lehman RA Jr, Dmitriev AE, Helgeson MD, Sasso RC, Kuklo TR, Riew KD: Salvage of C2 pedicle and pars screws using the intralaminar technique: a biomechanical analysis. Spine (Phila Pa 1976) 33:960-965, 2008

21. Ma XY, Yin QS, Wu ZH, Xia H, Liu JF, Xiang M, et al: C1 pedicle screws versus $\mathrm{C} 1$ lateral mass screws: comparisons of pullout strengths and biomechanical stabilities. Spine (Phila Pa 1976) 34:371-377, 2009

22. Magerl F, Seemann PS: Stable posterior fusion of the atlas and axis by transarticular screw fixation, in Kehr P, Weidner A (eds): Cervical Spine I. Vienna: Springer, 1987

23. Melcher RP, Puttlitz CM, Kleinstueck FS, Lotz JC, Harms J, Bradford DS: Biomechanical testing of posterior atlantoaxial fixation techniques. Spine (Phila Pa 1976) 27:2435-2440, 2002

24. Meyer D, Meyer F, Kretschmer T, Börm W: Translaminar screws of the axis - an alternative technique for rigid screw fixation in upper cervical spine instability. Neurosurg Rev 35:255-261, 2012

25. Miyakoshi N, Hongo M, Kobayashi T, Suzuki T, Abe E, Shimada Y: Comparison between bilateral $\mathrm{C} 2$ pedicle screwing and unilateral $\mathrm{C} 2$ pedicle screwing, combined with contralateral C2 laminar screwing, for atlantoaxial posterior fixation. Asian Spine J 8:777-785, 2014

26. Nagoshi N, Suda K, Morita T, Matsumoto S, Iimoto S, Yasui $\mathrm{K}$, et al: $\mathrm{C} 1$ posterior arch screw as an auxiliary anchor in posterior reconstruction for atlantoaxial dislocation associated with type II odontoid fracture: a case report and review of the literature. Springerplus 3:672, 2014
27. Nightingale RW, Winkelstein BA, Knaub KE, Richardson WJ, Luck JF, Myers BS: Comparative strengths and structural properties of the upper and lower cervical spine in flexion and extension. J Biomech 35:725-732, 2002

28. O'Donnell CM, Child ZA, Nguyen Q, Anderson PA, Lee MJ: Vertebral artery anomalies at the craniovertebral junction in the US population. Spine (Phila Pa 1976) 39:E1053-E1057, 2014

29. Park J, Scheer JK, Lim TJ, Deviren V, Ames CP: Biomechanical analysis of Goel technique for $\mathrm{C} 1-2$ fusion. J Neurosurg Spine 14:639-646, 2011

30. Resnick DK, Benzel EC: C1-C2 pedicle screw fixation with rigid cantilever beam construct: case report and technical note. Neurosurgery 50:426-428, 2002

31. Resnick DK, Lapsiwala S, Trost GR: Anatomic suitability of the C1-C2 complex for pedicle screw fixation. Spine (Phila Pa 1976) 27:1494-1498, 2002

32. Richter M, Schmidt R, Claes L, Puhl W, Wilke HJ: Posterior atlantoaxial fixation: biomechanical in vitro comparison of six different techniques. Spine (Phila Pa 1976) 27:17241732,2002

33. Savage JW, Limthongkul W, Park HS, Zhang LQ, Karaikovic EE: A comparison of biomechanical stability and pullout strength of two C1-C2 fixation constructs. Spine J 11:654658,2011

34. Tan M, Wang H, Wang Y, Zhang G, Yi P, Li Z, et al: Morphometric evaluation of screw fixation in atlas via posterior arch and lateral mass. Spine (Phila Pa 1976) 28:888-895, 2003

35. Uchino A, Saito N, Watadani T, Okada Y, Kozawa E, Nishi $\mathrm{N}$, et al: Vertebral artery variations at the C1-2 level diagnosed by magnetic resonance angiography. Neuroradiology $\mathbf{5 4 : 1 9 - 2 3 , 2 0 1 2 ~}$

36. Wright NM: Posterior C2 fixation using bilateral, crossing C2 laminar screws: case series and technical note. J Spinal Disord Tech 17:158-162, 2004

37. Yamazaki M, Okawa A, Furuya T, Sakuma T, Takahashi H, Kato K, et al: Anomalous vertebral arteries in the extra- and intraosseous regions of the craniovertebral junction visualized by 3-dimensional computed tomographic angiography: analysis of 100 consecutive surgical cases and review of the literature. Spine (Phila Pa 1976) 37:E1389-E1397, 2012

38. Young JP, Young PH, Ackermann MJ, Anderson PA, Riew KD: The ponticulus posticus: implications for screw insertion into the first cervical lateral mass. J Bone Joint Surg Am 87:2495-2498, 2005

39. Zarro CM, Ludwig SC, Hsieh AH, Seal CN, Gelb DE: Biomechanical comparison of the pullout strengths of $\mathrm{C} 1$ lateral mass screws and C1 posterior arch screws. Spine J 13:18921896,2013

\section{Disclosure}

The authors report no conflict of interest concerning the materials or methods used in this study or the findings specified in this paper.

\section{Author Contributions}

Conception and design: Huan. Acquisition of data: Guo-Xin. Analysis and interpretation of data: Guo-Xin. Drafting the article: Guo-Xin. Critically revising the article: both authors. Reviewed submitted version of manuscript: Huan. Approved the final version of the manuscript on behalf of both authors: Huan. Statistical analysis: Guo-Xin. Administrative/technical/material support: Guo-Xin. Study supervision: Huan.

\section{Correspondence}

Wang Huan, Department of Orthopaedic Surgery, Shengjing Hospital, China Medical University, Shenyang City, Liaoning Province 110004, China. email: 34332647@qq.com. 